\title{
Torsion Dystonia 6
}

National Cancer Institute

\section{Source}

National Cancer Institute. Torsion Dystonia 6. NCI Thesaurus. Code C156361.

An autosomal dominant condition caused by mutation(s) in the THAP1 gene, encoding THAP domain-containing protein 1. It is characterized by dystonic craniofacial movements, dysarthria, and dysphagia. Limb involvement is common. 